No. $3 / 03$

\title{
Money, Endogenous Fertility and Economic Growth
}

\author{
by \\ Alberto Petrucci \\ University of Molise, Department SEGeS \\ and \\ LUISS G. Carli, Department of Economics
}




\title{
ALBERTO PETRUCCI \\ Universita' del Molise and LUISS G. Carli \\ Campobasso and Rome, Italy \\ Money, Endogenous Fertility and Economic Growth*
}

\begin{abstract}
This paper analyzes the issue of money superneutrality through an intertemporal optimizing model of capital accumulation with endogenous fertility, i.e. endogenous population growth. Two elements of this setup invalidate money superneutrality: i) a demand for fertility that depends on real money balances, and ii) an inverse relation between capital-labor ratio and population growth. Higher monetary growth increases fertility, since it reduces its opportunity cost, and hence diminishes capital intensity, and per capita output. This reverse Tobin effect is matched by an increase in aggregate capital and output growth rates. In this framework, the optimal monetary growth rule is a "distorted Friedman rule". Keywords: Money superneutrality; Inflation; Fertility; Capital accumulation JEL classification: O42, O11, J13
\end{abstract}




\section{Introduction}

Sidrauski's (1967) result on money superneutrality, obtained within an intertemporal optimizing growth model with money in the utility function, strongly hinges on the validity of the modified golden rule. In fact, this condition, which states the equality between the marginal product of capital and the sum of the rate of time preference and population growth, determines in isolation capital stock when some assumptions on the economic environment are satisfied and, in addition, the population growth rate is constant. ${ }^{1}$

No attempts have been made so far to incorporate and analyze the hypothesis of an endogenous population growth rate within monetary models of capital accumulation. The purpose of this paper is to explore this neglected aspect of the theoretical literature through a simple monetary growth model à la Sidrauski, and investigate how the effects of anticipated inflation on capital accumulation and growth are affected.

The paper considers a model with an endogenous fertility choice, where the number of children enters directly into the utility function of consumers, ${ }^{2}$ along with consumption and real money balances.

We discover that the assumption of a variable population growth represents a source of money non-superneutrality not considered before. There are two crucial elements that invalidate money superneutrality in this setup: i) a demand for fertility that depends on financial wealth and hence on real money balances; and 
ii) an inverse relation between capital-labor ratio and population growth. A higher monetary growth rate increases fertility, as by reducing real balances holdings it diminishes the opportunity cost of one unit of fertility, which in turn stimulates people to increase fertility and hence results in a reduction of capital intensity, per capita output and consumption. However, the reverse Tobin effect on per capita output and capital is matched by an increase in aggregate output and capital growth rates, as these expansion rates coincide with fertility.

Moreover, we find that when population growth is endogenous, the optimal monetary policy rule is a distorted Friedman rule, which can call for either a contraction or an expansion of the money supply.

The paper is organized as follows. Section 2 presents the theoretical model. Section 3 analyzes the property of stability. Section 4 examines the steady state effects of higher money supply growth rate. Section 5 determines the optimal monetary policy rule and section 6 draws conclusions.

\section{The model}

Consider a monetary closed economy populated by identical agents who are infinitelylived, accumulate wealth in the form of money balances and physical capital, behave competitively and have perfect foresight. Money is introduced into the economy by inserting real balances into the utility function of economic agents.

The population size grows at an endogenously determined rate of expansion. This is obtained by inserting the fertility rate into the utility function of the repre- 
sentative agent and allowing it to be endogenously chosen; see, for the same demographic structure, Wang-Yip-Scotese (1994), Barro-Sala-i-Martin (1995), Palivos (1995), and Yip-Zhang (1997). The fertility rate corresponds to population growth because the mortality rate is zero and, as the economy is closed, there is no immigration from the rest of the world.

The representative agent makes consumption, fertility, and savings decisions in order to maximize the following intertemporal utility function

$$
\int_{0}^{\infty}[u(c, n)+v(m)] \exp (-\delta t) d t
$$

subject to the time allocation constraint

$$
l+h(n)=1
$$

the flow budget constraint

$$
c+\dot{m}+\dot{k}=f(k, l)+s-(n+\pi) m-n k
$$

and the initial condition $k(0)=k_{0}$,

where $c=$ per capita consumption; $n=$ fertility rate; $m=$ per capita real money balances; $l=$ labor; $h()=$ time spent for child-rearing; $k=$ per capita capital stock; $f($, )=per capita output; $s=$ per capita public lump-sum transfers; $\pi=$ actual inflation rate; and $\delta=$ rate of time preference (exogenous).

The instantaneous utility function is additively separable in consumption and fertility, on the one hand, and money holdings, on the other. The sub-utility 
function $u$ is twice-continuously differentiable, increasing and strictly concave in its arguments. $c$ and $n$ are assumed to be normal goods. Regarding the sub-utility function $v$, we assume that it is twice-continuously differentiable, strictly-concave and the marginal utility of money satisfies

$$
\operatorname{sgn}\left[v^{\prime}(m)\right]=\operatorname{sgn}\left(m^{\S}-m\right)
$$

where $m^{\S}$ gives the satiation level of real money balances. Therefore, the marginal utility of money is positive (negative), if $m<(>) m^{\S}$. See Friedman (1969) and Turnovsky-Brock (1980) for an identical hypothesis.

According to the time allocation constraint (2), the fixed time endowment (normalized to one) can be divided between labor and child-rearing. ${ }^{3}$ The function $h(n)$ represents the time cost of child-rearing, with $h(0)=0$ and -for $n>0-h>0$, $h^{\prime}>0$, and $h^{\prime \prime} \lessgtr 0 .{ }^{4}$

Per capita output is obtained by using capital and labor as inputs. The production function, $f($ ), satisfies the usual properties of regularity, exhibits constant returns to scale and satisfies the Inada conditions.

Total income available for consumption and savings takes into account the inflation tax on money holdings, population growth, which reduces per capita wealth, and includes government transfers.

After inserting the time constraint (2) into the production function for $l$, the present value Hamiltonian for the above dynamic optimization program is

$$
H=u(c, n)+v(m)+\lambda\{f[k, 1-h(n)]+s-(n+\pi) m-n k-c\}
$$


where $\lambda$ is the shadow value of wealth.

The first-order conditions for the consumer's optimization problem are

$$
\begin{gathered}
u_{c}(c, n)=\lambda \\
u_{n}(c, n)=\lambda\left\{f_{l}[k, 1-h(n)] h^{\prime}(n)+k+m\right\} \\
\dot{\lambda}-\lambda \delta=-\left[v^{\prime}(m)-\lambda(\pi+n)\right] \\
\dot{\lambda}-\lambda \delta=-\lambda\left\{f_{k}[k, 1-h(n)]-n\right\}
\end{gathered}
$$

The flow budget constraint (3) and the proper transversality conditions must also be satisfied at the optimum.

The first two equations (4a)-(4b) are the static efficiency conditions. According to equation (4a), the marginal utility of consumption must equal the marginal utility of wealth. Equation (4b) asserts that the marginal rate of substitution of consumption for fertility must equal the opportunity cost of one unit of fertility in output terms, given by the marginal product of labour times the marginal time-cost of child-rearing plus per capita total wealth.

Equations (4c) and (4d) derive from intertemporal arbitrage relationships, which implicitly state that in equilibrium the rate of return on consumption, 
given by $\delta-\dot{\lambda} / \lambda$, has to be equal to the real return on each asset, which are given by $v^{\prime}(m) / \lambda-(\pi+n)$, for real money balances, and $f_{k}[k, 1-h(n)]-n$, for capital.

Conditions (4) are necessary, but not sufficient for the optimum, since the production function $f($,$) in the budget constraint (3) may no longer be concave$ because of the external effect of $n$. The sufficient condition for a unique maximum requires that the Hessian of $H$ is negative definite. This condition is satisfied if, in addition to the strict concavity of the instantaneous utility function and the production function, the opportunity cost of children in terms of output, $f_{l} h^{\prime}$, is strictly increasing in $n$, i.e. $f_{l l}\left(h^{\prime}\right)^{2}-f_{l} h^{\prime \prime}<0$. We assume that the latter condition holds throughout.

The goods market equilibrium condition requires

$$
f[k, 1-h(n)]=c+\dot{k}+n k
$$

where the time allocation constraint (2) has been used.

The monetary authority allows the nominal money supply to grow at a constant rate, given by $\theta$. Therefore, the evolution of real money balances per capita is

$$
\dot{m}=m(\theta-\pi-n)
$$

Finally, the seigniorage from money creation is transferred to the private sector in a lump-sum fashion: 


$$
s=\theta m
$$

\section{Stability analysis}

The general macroeconomic equilibrium -obtained by combining the optimality conditions (4) together with equations (5), (6) and (7)- is given by the following set of equations

$$
\begin{gathered}
u_{c}(c, n)=\lambda \\
u_{n}(c, n)=\lambda\left\{f_{l}[k, 1-h(n)] h^{\prime}(n)+k+m\right\} \\
v^{\prime}(m)=\lambda\left\{f_{k}[k, 1-h(n)]+\pi\right\} \\
\dot{\lambda}=\lambda\left\{\delta+n-f_{k}[k, 1-h(n)]\right\} \\
\dot{m}=m(\theta-\pi-n) \\
f[k, 1-h(n)]=c+\dot{k}+n k
\end{gathered}
$$

together with the transversality conditions. ${ }^{5}$ 
Equations (8a)-(8c) may be solved for $c, n$ and $\pi$ in terms of the endogenous dynamic variables $(\lambda, m, k)$ in the form:

$$
\begin{gathered}
c=c(\lambda, m, k), \quad c_{\lambda}=\Xi / \Sigma<0 ; c_{m}=-\bar{\lambda} u_{c n} / \Sigma \lessgtr 0 ; c_{k}=-\bar{\lambda}-u_{c n} / \Sigma \gtrless 0 ; \\
n=n(\lambda, m, k), \quad n_{\lambda}=-\Psi / \Sigma<0 ; n_{m}=\bar{\lambda} u_{c c} / \Sigma<0 ; n_{k}=\bar{\lambda}-u_{c c} / \Sigma<0 ; \\
\pi=\pi(\lambda, m, k), \quad \pi_{\lambda}=-\left[\bar{\lambda} f_{k l} h^{\prime} \Psi+(\delta+\theta) \Sigma\right] / \Sigma<0 ;
\end{gathered}
$$$$
\pi_{m}=\left[v^{\prime \prime} \Sigma+\bar{\lambda}^{2} f_{k l} h^{\prime} u_{c c}\right] / \Sigma<0 ; \pi_{k}=-\bar{\lambda}\left(f_{k k} \Sigma-f_{k l} h^{\prime}-u_{c c}\right) / \Sigma \gtrless 0 ;
$$

where overbar variables denote long-run equilibrium values and $\Xi=u_{n n}-\left(u_{n} / u_{c}\right) u_{c n}-$ $u_{c}\left[f_{l l}\left(h^{\prime}\right)^{2}-f_{l} h^{\prime \prime}\right]<0 ; \Psi=u_{c n}-\left(u_{n} / u_{c}\right) u_{c c}>0 ; \Sigma=\Xi u_{c c}-\Psi u_{c n}>0 ;$ and - $=1+h^{\prime} f_{k l}>0$.

By substituting the above short-run solutions for $c, n$ and $\pi$ in equations (8d), (8e) and (8f), linearizing the sub-system (10) around the long-run equilibrium, we obtain the following autonomous dynamic system

$$
\left[\begin{array}{c}
\dot{\lambda} \\
\dot{m} \\
\dot{k}
\end{array}\right]=\frac{1}{\Sigma}\left[\begin{array}{lll}
\eta_{11} & \eta_{12} & \eta_{13} \\
\eta_{21} & \eta_{22} & \eta_{23} \\
\eta_{31} & \eta_{32} & \eta_{33}
\end{array}\right]\left[\begin{array}{c}
\lambda-\bar{\lambda} \\
m-\bar{m} \\
k-\bar{k}
\end{array}\right]
$$


where

$$
\begin{aligned}
& \eta_{11}=-\bar{\lambda} \Psi-<0 ; \quad \eta_{12}=\bar{\lambda}^{2}-u_{c c}<0 ; \quad \eta_{13}=\bar{\lambda}\left(\bar{\lambda}-{ }^{2} u_{c c}-\Sigma f_{k k}\right) \gtrless 0 ; \\
& \eta_{21}=\bar{m}\left[\bar{\lambda} \Psi-+\left(f_{k}+\bar{\pi}\right) \Sigma\right] / \bar{\lambda}>0 ; \quad \eta_{22}=-\bar{m}\left(v^{\prime \prime} \Sigma+\bar{\lambda}^{2}-u_{c c}\right) / \bar{\lambda}>0 ; \\
& \eta_{23}=-\bar{m}\left(\bar{\lambda}-{ }^{2} u_{c c}-\Sigma f_{k k}\right) \gtrless 0 ; \quad \eta_{31}=\Gamma \Psi-\Xi>0 ; \quad \eta_{32}=\bar{\lambda}\left(u_{c n}-\Gamma u_{c c}\right) \gtrless 0 ; \\
& \eta_{33}=\delta \Sigma+\bar{\lambda}-\left(u_{c n}-\Gamma u_{c c}\right) \gtrless 0 ; \text { and } \Gamma=f_{l} h^{\prime}+\bar{k}>0 .
\end{aligned}
$$

Since the economy has two jump variables, $\lambda$ and $m$, and one predetermined variable, $k$, saddle-point stability requires that the matrix of coefficients in model (10) must have a negative determinant, since it must admit two positive and one negative eigenvalues. Thus for this requisite to be satisfied, it is required that

$$
\begin{aligned}
& \Delta=-v^{\prime \prime}\left[\Psi\left(\delta--\Gamma f_{k k}\right)+\Xi f_{k k}-\bar{\lambda}-{ }^{2}\right]+ \\
& +\bar{\lambda}\left(f_{k}+\bar{\pi}\right)\left[f_{k k}\left(u_{c n}-\Gamma u_{c c}\right)+\delta-u_{c c}\right]>0
\end{aligned}
$$

The determinant condition (11) does not per se guarantee that we have two positive characteristic roots and a negative one, as it could be also satisfied with three negative roots leading to a globally stable economy instead of a saddle-point equilibrium. Since the trace of the state matrix in (10), given by $\delta-v^{\prime \prime} \bar{m} / \bar{\lambda}$, is unambiguously positive, we are ensured that, once condition (11) holds, the dynamic system is saddle-point stable.

\section{Long-run effects of money supply growth}

The core steady state equilibrium model is 


$$
\begin{gathered}
\frac{u_{n}(\bar{c}, \bar{n})}{u_{c}(\bar{c}, \bar{n})}=f_{l}[\bar{k}, 1-h(\bar{n})] h^{\prime}(\bar{n})+\bar{k}+\bar{m} \\
\frac{v^{\prime}(\bar{m})}{u_{c}(\bar{c}, \bar{n})}=\delta+\theta \\
f_{k}[\bar{k}, 1-h(\bar{n})]=\delta+\bar{n} \\
f[\bar{k}, 1-h(\bar{n})]=\bar{c}+\bar{n} \bar{k}
\end{gathered}
$$

There are some special features of the long-run equilibrium that must be emphasized. First, the demand for fertility, derived from equation (12a), is strictly interconnected with the monetary side of the economy as it depends directly on financial wealth and hence on real money balances. ${ }^{6}$ Second, the modified golden rule, i.e. equation (12c), no longer determines capital intensity by itself, but establishes an inverse relationship between capital stock (as well as capital intensity) and population growth. ${ }^{7}$ These two elements allow for the violation of money superneutrality. Third, while per capita variables have no long-run growth, aggregate variables grow at the endogenous rate $\bar{n}$.

The basic steady state effects of money supply growth are given by:

$$
\begin{aligned}
& \frac{d \bar{k}}{d \theta}=-\bar{\lambda}-u_{n} / \Delta<0 ; \\
& \frac{d \bar{n}}{d \theta}=-\bar{\lambda} f_{k k} u_{n} / \Delta>0 ; \\
& \frac{d \bar{c}}{d \theta}=-\left[\bar{\lambda}\left(\delta--\Gamma f_{k k}\right) u_{n}\right] / \Delta<0 ;
\end{aligned}
$$




$$
\frac{d \bar{m}}{d \theta}=-\left[\Psi\left(\delta--\Gamma f_{k k}\right)+\Xi f_{k k}-\bar{\lambda}-{ }^{2}\right] u_{n} / \Delta<0 ;
$$

where $\Delta>0$ has been defined in (11).

An increase in the rate of monetary growth raises the implicit cost of holding money, i.e. $f_{k}+\bar{\pi}=\delta+\theta$, and hence reduces real money balances. The lower money holdings in turn stimulate (for a given level of consumption) fertility, because the opportunity cost of one unit of fertility, namely $f_{l} h^{\prime}+\bar{k}+\bar{m}$ diminishes (for a given capital stock). This latter effect generates, through the modified golden rule, a decline in the demand for capital that brings about a reduction of per capita output and consumption. The higher monetary growth also reduces labor effort, since the rise in fertility implies a larger consumption of time for child-rearing which lowers the time that can be devoted to work. The marginal product of capital, which in equilibrium is equal to $\delta+\bar{n}$, increases and the capital-labor ratio declines.

The basic comparative statics results can be illustrated with the aid of Fig. $1 .^{8}$ Here is drawn the marginal product of capital schedule, given by the $f_{k}[\bar{k}, 1-h(\bar{n})]$ schedule, where $\bar{n}$ is parametrically given; this schedule is downward sloping and asymptotically reaches the horizontal axis. A parametric increase in the fertility rate shifts the marginal product of capital schedule down. The other schedule in Fig. 1 is the adjusted rate of time preference schedule, namely the $\delta+\bar{n}$ schedule, drawn horizontally as it is independent of $\bar{k}$.

[Insert Fig. 1 about here] 
By raising fertility, the monetary expansion rate shifts the $\delta+\bar{n}$ schedule upward and the $f_{k}[\bar{k}, 1-h(\bar{n})]$ schedule downward. The equilibrium moves from point $\mathrm{A}$ to point $\mathrm{B}$ in Fig. 1 with an accompanied fall in capital stock and capital intensity. ${ }^{9}$ The thick curve drawn in the diagram represents the equation $f_{k}[\bar{k}, 1-h(\bar{n})]=\delta+\bar{n}$, which implies the inverse relationship between $\bar{n}$ and $\bar{k}$, being a part of the driving forces of the results.

Inflation is increased by the shock, but by less than the rise in $\theta$ because of the higher fertility rate. ${ }^{10}$ Since the real interest rate is increased, the Fisher relation is invalidated. However, the nominal interest rate follows one-to-one the increase of the money supply growth.

The money supply growth rate unambiguously lowers steady state welfare, that is, the negative consequences on consumption and real money balances overcompensate the positive effect exerted on fertility.

In addition, it is worth noticing that while a higher money growth rate lowers capital intensity and per capita output -i.e. a reverse Tobin effect in per capita terms occurs- and leaves their long-run rate of expansion unaffected, it increases the growth rate of capital and output levels (because they grow at rate $\bar{n}$ ). That is, we have a sort of Tobin effect in aggregate growth terms.

Finally, two comments are in order. First, despite the model based on endogenous fertility is similar to the corresponding model with an endogenous laborleisure choice, ${ }^{11}$ the two models are qualitatively non-equivalent as the long-run effects of inflation differ substantially. In fact, money is superneutral in the model 
with an endogenous labor supply if preferences are separable in consumptionleisure and money balances. See, for example, Brock (1974) and Wang-Yip (1992). The model with endogenous fertility, on the contrary, exhibits a reverse Tobin effect when preferences are separable in consumption-fertility and money balances.

The similarity between the two models is due to the apparently identical role of leisure and fertility. Fertility is at the same time a good as well as an input, like leisure. Differently from leisure, however, fertility enters the private budget constraint (3) not only through the production function, but also through the term $(n+\pi) m+n k$. This element makes the demand for fertility depend on real money balances, creating an interdependence between the real and monetary sides of the economy and accounting for the different results between the two models.

Second, our results are based on preferences which are separable in consumptionfertility and real balances. ${ }^{12}$ Some curiosity emerges about what would happen if fertility were not separable from real balances in the instantaneous utility function, while it could be separable from consumption. When the instantaneous utility function is of the type $w(c)+z(n, m)$, equation (12a) must be replaced by the following relationship ${ }^{13}$

$$
\frac{z_{n}(\bar{n}, \bar{m})}{w^{\prime}(\bar{c})}=f_{l}[\bar{k}, 1-h(\bar{n})] h^{\prime}(\bar{n})+\bar{k}+\bar{m}
$$

This implies that the demand for fertility can be implicitly expressed as ${ }^{14}$

$$
\bar{n}=\mathbf{n}(\bar{c}, \bar{m}, \bar{k}), \quad \mathbf{n}_{c}>0, \mathbf{n}_{m} \lessgtr 0, \mathbf{n}_{k}<0
$$


The implications of the new preferences considered depend entirely on the implied interaction between the real and the monetary sides of the economy. This interaction is governed by $\operatorname{sgn}\left(\mathbf{n}_{m}\right)=\operatorname{sgn}\left(z_{n m}-w^{\prime}\right)$. The model exhibits a reverse Tobin effect if $\mathbf{n}_{m}<0$; this happens when $w^{\prime}>z_{n m}$, regardless the sign of $z_{n m}$. Therefore a possible Tobin effect may only arise if $z_{n m}>w^{\prime}>0$.

This example demonstrates once more, within the money in the utility function approach, the substantial difference between the endogenous fertility and the elastic labor supply hypotheses. If an instantaneous utility function separable in consumption and leisure-money was considered in the model with elastic laborleisure choices, a higher $\theta$ would result in a reverse Tobin effect only when the marginal utility of leisure is decreasing in money balances.

\section{Optimal monetary growth rule}

Determination of steady state optimal monetary growth is based on the assumption that the government seeks to maximize the welfare function of the representative agent subject to the model of the economy, given by system (12) as a constraint.

We can make some simplifications. If we express consumption (by using simultaneously the modified golden rule and the resources constraint) and the population growth rate (by employing equation 12c) as implicit functions of capital stock -i.e. $\bar{c}=\hat{c}(\bar{k})$ and $\bar{n}=\hat{n}(\bar{k})$ respectively- and capital stock (by using equations $12 \mathrm{a}, 12 \mathrm{c}$, and $12 \mathrm{~d})$ as a function of real money balances -i.e. $\bar{k}=\hat{k}(\bar{m})-$, the 
determination of the optimal $\theta$ can be found by solving the following problem

$$
\max _{\bar{k}, \bar{m}, \theta}\{u[\hat{c}(\bar{k}), \hat{n}(\bar{k})]+v(\bar{m})\}
$$

subject to

$$
\bar{k}=\hat{k}(\bar{m})
$$

and

$$
v^{\prime}(\bar{m})=(\delta+\theta) u_{c}[\hat{c}(\bar{k}), \hat{n}(\bar{k})]
$$

where

$\hat{c}_{k}=\left[\delta--\Gamma f_{k k}\right] /->0 ; \hat{n}_{k}=f_{k k} /-<0 ; \hat{k}_{m}=\bar{\lambda}-/\left[\Psi\left(\delta--\Gamma f_{k k}\right)+\Xi f_{k k}-\bar{\lambda}\right.$ $\left.-{ }^{2}\right]>0$.

The first order conditions for the optimum are

$$
\begin{gathered}
u_{c} \hat{c}_{k}+u_{n} \hat{n}_{k}=-\mu_{1} \\
v^{\prime}=\mu_{1} \hat{k}_{m} \\
\bar{k}^{*}=\hat{k}\left(\bar{m}^{*}\right) \\
v^{\prime}\left(\bar{m}^{*}\right)=\left(\delta+\theta^{*}\right) u_{c}\left[\hat{c}\left(\bar{k}^{*}\right), \hat{n}\left(\bar{k}^{*}\right)\right]
\end{gathered}
$$


where $\mu_{1}$ is the Lagrange multiplier associated with constraint (13b) and asterisks denote the socially optimal steady state values. ${ }^{15}$ The endogenous variables of system (14) are $\bar{k}^{*}, \bar{m}^{*}, \mu_{1}$ and $\theta^{*}$.

Substituting relationships (14a), (14b) and (14c) into equation (14d), the optimal monetary growth rate can be expressed as

$$
\begin{gathered}
\theta^{*}=\bar{\lambda}^{*} \frac{\left\{\delta \frac{\partial\left(f_{k}-\bar{n}\right)}{\partial \bar{n}}-\frac{\partial f_{k}}{\partial \bar{k}}\left[\frac{u_{n}}{u_{c}}+\frac{\partial(f-\bar{n} \bar{k})}{\partial \bar{n}}\right]\right\}}{\left[\Psi\left(\delta--\Gamma f_{k k}\right)+\Xi f_{k k}-\bar{\lambda}^{*}-{ }^{2}\right]}-\delta= \\
=-\frac{\bar{\lambda}^{*}\left(\delta-+\bar{m}^{*} f_{k k}\right)}{\left[\Psi\left(\delta--\Gamma f_{k k}\right)+\Xi f_{k k}-\bar{\lambda}^{*}-2\right]}-\delta \gtrless 0
\end{gathered}
$$

From equation (15), we see that in our context the Friedman full liquidity rule -i.e. $\theta^{* F}=-\delta$ or $f_{k}+\pi=0$ - is not optimal, since the money supply growth rate affects the fertility choice, which distorts the long-run capital intensity. The optimal monetary policy rule requires a balancing for the partial effects exerted by the population growth on both the net and the gross return on capital. These effects are negative, but enter equation (15) with both positive and negative signs. The rule specified in (15) can prescribe either a contraction or an expansion rate of money supply. Accordingly, the nominal interest rate corresponding to $\theta^{*}$ can be either negative or positive. If $\delta+\theta^{*}$ is negative (positive), the optimum quantity of money balances must be pushed beyond (kept below) the satiation level $m^{\S}$, as $v^{\prime}<(>) 0$.

Also in terms of the normative analysis, the difference between the monetary growth model with endogenous fertility and the monetary growth model with 
an endogenous labor supply is substantial. In the latter model when the instantaneous utility function is separable in consumption-leisure and money, the Friedman rule is optimal since money is superneutral.

\section{Concluding remarks}

This paper has examined the steady state consequences of the money supply growth rate in an optimizing monetary model of capital accumulation with endogenous population growth.

The analysis identifies a source of non-superneutrality not studied before. When endogenous population growth is incorporated into Sidrauski's monetary growth model, the modified golden rule is incapable of fully determining the capital-labor ratio, since capital intensity becomes interdependent with other variables of the model through the fertility choice. An inverse relation between per capita capital stock and population growth, together with a fertility demand that depends on financial wealth, is the crucial element at the root of the nonsuperneutrality of money discovered in the present setup. By reducing the real balances holdings, a higher monetary growth rate diminishes the opportunity cost of fertility, which in turn stimulates people to increase fertility and hence results in a reduction of capital intensity.

The reverse Tobin effect on per capita output and capital is matched by an increase in aggregate output and capital growth rates.

In this framework, the optimal monetary growth rule can call for either a 
contraction or an expansion of money supply.

Finally, despite similarities with the model that incorporates an endogenous labour supply into the money in the utility function approach, the model with an endogenous fertility choice exhibits quite different positive and normative results in terms of inflation and growth analysis. 


\section{References}

Barro, Robert J., and Gary Becker. "Fertility Choice in a Model of Economic Growth." Econometrica 57 (March 1989): 481-501.

Barro, Robert J., and Xavier Sala-i-Martin. Economic Growth. New York: McGraw-Hill, 1995.

Brock, William A. "Money and Growth: The Case of Long-Run Perfect Foresight." International Economic Review 15 (October 1974): 750-77.

Carmichael, Jeffrey. "Money and Growth: Some Old Theorems from a New Perspectives." Economic Record 58 (December 1982): 386-94.

Danthine, Jean-Pierre, Donaldson John, and Lance Smith. "On the Superneutrality of Money in a Stochastic Dynamic Macroeconomic Model." Journal of Monetary Economics 20 (December 1987): 475-99.

Epstein, Larry G., and J. Allan Hynes. "The Rate of Time Preference and Dynamic Economic Analysis." Journal of Political Economy 91 (August 1983): $611-53$.

Friedman, Milton. "The Optimum Quantity of Money." In The Optimum Quantity of Money and Other Essays, edited by M. Friedman. Chicago: Aldine, 1970: $1-50$.

Hayakawa, Hiroaki." The Non-Neutrality of Money and the Optimal Monetary Growth Rule when Preferences are Recursive: Cash-in-Advance versus Money in the Utility Function." Journal of Macroeconomics 14 (Spring: 1992): 233-66.

Nerlove, Marc, and Lakshmi K. Raut. "Growth Models with Endogenous 
Population: A General Framework.". In Handbook of Population and Family Economics, edited by Mark R. Rosenzweig and Oded Stark. Amsterdam: NorthHolland, vol 1B, 1997: 1117-74.

Orphanides, Athanasios, and Robert M. Solow."Money, Inflation and Growth." In Handbook of Monetary Economics, edited by Friedman Benjamin and Frank H. Hahn. Amsterdam: North-Holland, vol I, 1990: 223-61.

Palivos, Theodore. "Endogenous Fertility, Multiple Growth Paths, and Economic Convergence." Journal of Economic Dynamics and Control 19 (November 1995): 1489-1510.

Razin, Assaf-Ben, and Uri Zion. "An Intergenerational Model of Population Growth." American Economic Review 65 (December 1995): 923-33.

Sidrauski, Miguel. "Rational Choice and Patterns of Growth in a Monetary Economy." American Economic Review, Papers and Proceedings, 57 (May 1967): $534-44$.

Turnovsky, Stephen J., and William A. Brock. "Time Consistency and Optimal Government Policies in Perfect Foresight Equilibrium." Journal of Public Economics 13 (April 1980): 183-212.

Wang, Ping, and Chong K. Yip." Alternative Approaches to Money and Growth." Journal of Money, Credit and Banking 24 (November 1992): 553-62.

Wang, Ping, Yip, Chong K., and Carol A. Scotese. "Fertility Choice and Economic Growth: Theory and Evidence." Review of Economics and Statistics 76 (May 1994): 255-66. 
Yip, Chong K., and Junxi Zhang. "A Simple Endogenous Growth Model with Endogenous Fertility: Indeterminacy and Uniqueness." Journal of Population Economics 10 (February 1997): 97-110.

Zhang, Junxi. "Inflation and Growth: Pecuniary Transactions Costs and Qualitative Equivalence." Journal of Money, Credit and Banking 32 (February 2000): $1-12$. 


\section{Appendix}

\section{Mathematical notation}

$c=$ per capita consumption.

$n=$ fertility rate.

$u()=$, sub-utility function.

$m=$ per capita real money balances.

$v()=$ sub-utility function.

$m^{\S}=$ satiation level of per capita real money balances.

$t=$ time.

$\delta=$ rate of time preference (exogenous).

$l=$ labor.

$h()=$ time spent for child-rearing.

$k=$ per capita capital stock.

$f()=$, per capita output.

$s=$ per capita public lump-sum transfers.

$\pi=$ actual inflation rate.

$\lambda=$ shadow value of wealth.

$\theta=$ nominal money supply growth rate. 


\section{NOTES}

* This paper was written while the author was visiting Columbia University and revised during his visit to Stanford University. The author would like to thank, without holding them responsible for errors and omissions, Philip Cagan, Filippo Cesarano, Ned Phelps, Furio Rosati, participants at the Money, Macro and Finance Conference of London, three anonymous referees and one Editor of the Journal, Theodore Palivos, for constructive comments and helpful suggestions. CNR has provided financial assistance.

1 The main "environmental" assumptions that support money superneutrality are: i) infinitely-lived agents; ii) a constant subjective discount rate; iii) a rate of return on capital independent of real money balances; iv) an exogenous labor supply; and v) the absence of uncertainty. See Carmichael (1982), DanthineDonaldson-Smith (1987), and Orphanides-Solow (1990).

${ }^{2}$ In this regard, we employ the standard practice of the literature on optimizing real growth models with endogenous fertility; see, for example, Razin-Ben-Zion (1975), Barro-Becker (1989), Palivos (1995), and Nerlove-Raut (1997).

${ }^{3}$ We follow Wang-Yip-Scotese (1994) and Palivos (1995) on using a time allocation constraint where the fertility rate indirectly enters. Alternatively, BarroSala-i-Martin (1995) considers explicitly a child-rearing cost function (which de- 
pends directly on $n$ and $k$ ) in the budget constraint of the representative consumer. None of our results would change under the Barro-Sala-i-Martin approach.

${ }^{4}$ When $h^{\prime \prime}<0$, there are economies of scale in child-rearing; see Palivos (1995) for a discussion.

${ }^{5}$ Lump-sum transfers are omitted, since they can be solved residually.

${ }^{6}$ From equation (12a), the demand for fertility can implicitly be stated as:

$$
\bar{n}=\tilde{n}(\bar{c}, \bar{m}, \bar{k}), \quad \tilde{n}_{c}>0, \tilde{n}_{m}<0, \tilde{n}_{k}<0
$$

7 This is the exact opposite of Malthus's prediction (see, e.g., Barro-Sala-iMartin, 1995, and Yip-Zhang, 1997).

8 The illustration of Fig. 1 was suggested by one referee.

${ }^{9}$ If $\bar{n}$ is invariant as in Sidrauski's model, nothing will happen against monetary expansion. If the rate of time preference $\delta$ is a function of consumption and real balances (as in Epstein-Hynes, 1983, and Hayakawa, 1992), hence a function of capital intensity and real balances, the $\delta+\bar{n}$ schedule, having a curvature (increasing first and decreasing later), will shift downward as real balance holdings fall, giving rise to the non-superneutrality of money in the direction of the Tobin effect. 
10 The endogeneity of population growth breaks the one-to-one correspondence of the long-run inflation rate with the money supply growth rate as it typically occurs in neoclassical models with constant population growth.

11 This can be clearly seen if we re-write the long-run model in terms of $\bar{l}$ by eliminating $\bar{n}=h^{-1}(1-\bar{l})$.

12 Note however that the results obtained above still hold if $u_{c n}=0$.

13 Also equation (12b) changes functionally, but not qualitatively.

14 Equation (12a"') is the surrogate of equation (12a') in note 6.

15 The maximization problem (13) admits another necessary condition, namely $\mu_{2} u_{c}=0$, where $\mu_{2}$ is the Lagrange multiplier associated with constraint (13c). This condition, which implies $\mu_{2}=0$, has been included in system (14). The alternative case contained in such a condition, i.e. $u_{c}=0$, is not possible, since it would imply from model $(12)$ that $u_{c}=u_{n}=v^{\prime}=0$, which yields optimal values for $\bar{c}^{*}, \bar{n}^{*}, \bar{m}^{*}$, and (through the modified golden rule) $\bar{k}^{*}$ inconsistent with the resources constraint $(12 \mathrm{~d})$. 


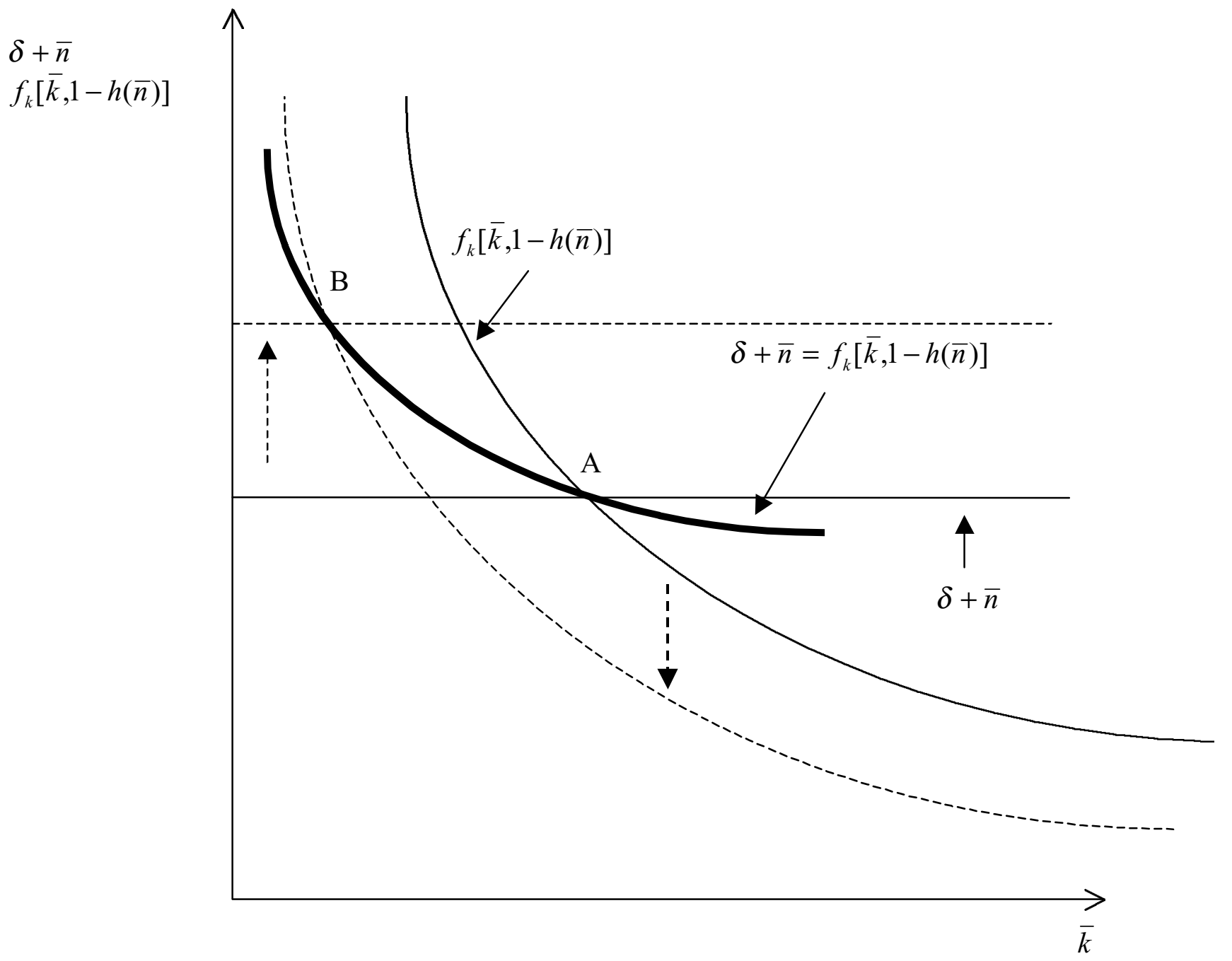

Figure 1 